“C 2011 IEEE. Personal use of this material is permitted. Permission from IEEE must be obtained for all other uses, in any current or future media, including reprinting/republishing this material for advertising or promotional purposes, creating new collective works, for resale or redistribution to servers or lists, or reuse of any copyrighted component of this work in other works." 


\title{
Simple and Robust Predictive Direct Control of DFIG with Low Constant Switching Frequency and Reduced Torque and Flux Ripples
}

\author{
Jiefeng $\mathrm{Hu}^{1}$, Jianguo $\mathrm{Zhu}^{1}$, Yongchang Zhang ${ }^{1}$, Qishuang $\mathrm{Ma}^{2}$ and Youguang Guo ${ }^{1}$ \\ ${ }^{1}$ School of Electrical, Mechanical and Mechatronic Sy stems, University of Technology, Sydney, Australia \\ ${ }^{2}$ School of Automation Science and Electrical Engineering, Beijing University of Aeronautics \& Astronautics, China \\ E-mail: Jiefeng.Hu@student.uts.edu.au
}

\begin{abstract}
For conventional direct torque control (CDTC) methods, there are usually undesired torque and flux ripples mainly for two reasons. First, the vectors selected are not necessary the best. Secondly, one-step delay influence in digital implementation causes additional torque and flux ripples. This paper proposes a novel predictive direct torque control (PDTC) strategy of the doubly fed induction generator (DFIG). The proposed strategy aims to reduce torque and flux ripples effectively at low constant switching frequency by appropriately arranging two active vectors followed by one zero vector within one control period. Furthermore, one-step delay is compensated using a mode-based prediction scheme. Finally, the control system is simplified through further analysis of the transient slope of torque and flux without performance degradation. Simulation results validate the proposed strategy with excellent steady-state and transient performance, which makes it very suitable for wind power generation.
\end{abstract}

\section{INTRODUCTION}

Direct torque control (DTC) was proposed in 1980s and since then it was well developed in power electronics and drives application for its excellent steady-state and transient performance [1], [2]. Compared to field oriented control (FOC) technique [3], DTC system is very simple and robust because current regulators and complicate coordinate transformation are eliminated. However, due to the fixed sampling frequency and limited minimum hysteresis bands, both torque and flux exceed the bands imposed by the hysteresis comparators, which lead to undesired torque and flu $x$ ripples. Another reason for large torque and flu x ripples is that the selected voltage vector based on the classic DTC table is not necessarily the most suitable one. On the other hand, the slopes of the electromagnetic torque and flux vary according to different operating conditions and time interval, variable switching frequency behavior is unavoidable. These two main drawbacks of conventional DTC (CDTC) have become the obstacle for high power application such as wind power generation.

In order to address the issues mentioned above, many improved schemes have been proposed in the last few years. Space vector modulation (SVM) is incorporated with DTC to generate voltage vectors which can regulate torque and flux more effectively at fixed switching frequency [4], [5]. In SVM-DTC scheme, rotating reference frame transformation is required. Another solution is to use a constant switching frequency torque controller to replace the conventional hysteresis-based controller [6], [7]. However, PI controllers and triangular waveform generators are required, which result in complex control system.

More recently predictive direct control was proposed to obtain even better performance. [8] presented a predictive direct torque control (PDTC) strategy for a doubly fed induction machine. The torque and flux ripples are reduced considerably even at low constant switching frequency by applying three appropriate vectors in one control period. However, it requires complicated calculation to obtain the vectors applied durations. Besides, two switching tables are used and sub- or hyper-synchronism identification is mandatory. A model-based predictive direct control strategy was proposed to regulate the stator power of DFIG in [9]. The stator active and reactive power variations between $k$ th and $(k+1) t h$ instant are predict with the machine model and the system variables at $k$ th instant, which is used to determine the required voltage vector to eliminate the power errors. SVM is then employed to achieve constant switching frequency. However, the predicted variations depend on the machine parameters. Besides, a transformation to a rotating reference frame is required and the switching frequency is still relatively high. Another mode-based predictive strategy was presented in [10]. The torque and flux variations are predicted with in a similar way to [9] while the ripples reduction at constant switching frequency is achieved by selecting the best vector based on a cost function in every sampling period. Again, complicate calculation is required because the effects of each voltage vector need to be evaluated. [11] presented a deep analysis of the time delay influences in discrete implementation, taking data transmission to CPU, data calculation in CPU and switching signals to inverter into account. After that, a prediction scheme with low computational complexity and low parameter sensitivity is proposed to diminish both the torque and flux ripples.

Combining the merits of the predictive direct control methods mentioned above, this paper proposes a novel PDTC strategy of DFIG for wind power generation application, with reduced torque and flux ripples, and a low constant switching frequency. In section II, the effect of voltage vectors on electromagnetic torque and rotor flux is investigated. The 


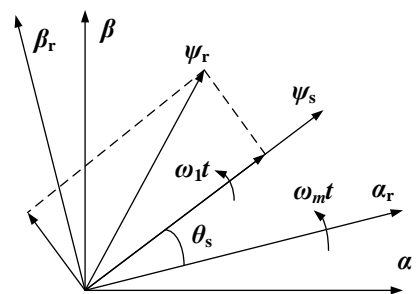

Fig. 1. Stator and rotor flux in stationary and rotor reference frames

principle of proposed PDTC is given in section III while the system simplification and parameter variation effect are illustrated in section IV followed by the simulation result in section V. Finally, the conclusions are drawn in section VI.

\section{ANALYSIS OF VOLT AGE VECTORS EFFECT ON TORQUE AND FLUX}

\section{A. DFIG modelling}

In the rotor reference frame rotating at an angular speed of $\omega_{m}$, the DFIG mathematical equations can be expressed as follow:

$$
\begin{gathered}
\vec{v}_{s}=R_{s} \vec{i}_{s}+\frac{d \vec{\psi}_{s}}{d t}+j \omega_{m} \vec{\psi}_{s} \\
\vec{v}_{r}=R_{r} \vec{i}_{r}+\frac{d \vec{\psi}_{r}}{d t} \\
\vec{\psi}_{s}=L_{s} \vec{i}_{s}+L_{m} \vec{i}_{r} \\
\vec{\psi}_{r}=L_{m} \vec{i}_{s}+L_{r} \vec{i}_{r} \\
T_{e}=\frac{3}{2} p \lambda L_{m} \vec{\psi}_{r} \otimes \vec{\psi}_{s}=\frac{3}{2} p \lambda L_{m} \operatorname{Im}\left\{\vec{\psi}_{r}^{*} \vec{\psi}_{s}\right\}
\end{gathered}
$$

where $\vec{v}_{s}, \vec{v}_{r}, \vec{i}_{s}, \vec{i}_{r}, \vec{\psi}_{s}$ and $\vec{\psi}_{r}$ are the stator voltage vector, rotor voltage vector, stator current vector, rotor current vector, stator flux vector and rotor flux vector, respectively. $R_{s}, R_{r}, L_{s}$, $L_{r}$ and $L_{m}$ are the stator resistance, rotor resistance, stator inductance, rotor inductance and mutual inductance, respectively. $p$ is the pole pairs and $\lambda=1 /\left(L_{s} L_{r}-L_{m}{ }^{2}\right)$.

\section{B. Voltage Vectors Effect on Torque and Flux}

The spatial relationship between stator flux and rotor flux is shown in Fig. 1. The stator flux in the rotor $\alpha_{\mathrm{r}}-\beta_{\mathrm{r}}$ frame can be expressed as:

$$
\vec{\psi}_{s}=\left|\vec{\psi}_{s}\right| e^{j \theta_{s}}
$$

Where $\theta_{\mathrm{s}}$ is the angle between $\psi_{s}$ and rotor $\alpha_{\mathrm{r}}$ axis. The differentiation of stator flux with respect to time can be expressed as:

$$
\frac{d \vec{\psi}_{s}}{d t}=\frac{d\left(\left|\vec{\psi}_{s}\right| e^{j \theta_{s}}\right)}{d t}=j\left|\vec{\psi}_{s}\right| e^{j \theta_{s}} \frac{d \theta_{s}}{d t}=j\left(\omega_{1}-\omega_{m}\right) \vec{\psi}_{s}=j \omega_{s} \vec{\psi}_{s}
$$
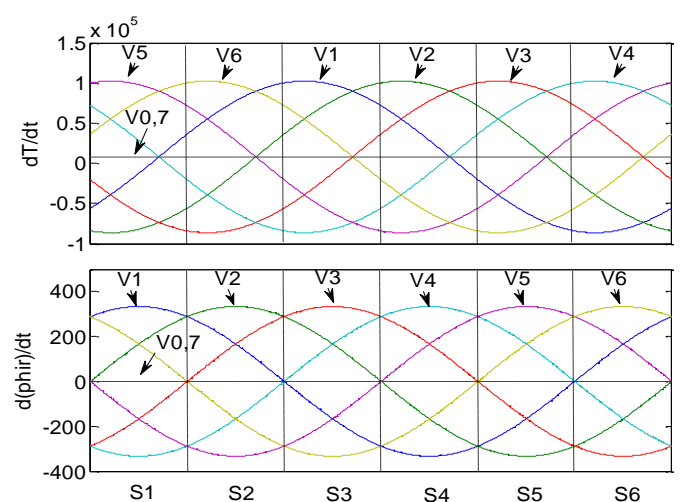

Fig. 2. Torque and flux slopes versus rotor flux position for different rotor voltage vectors at sub-synchronism.

Where $\omega_{1}$ and $\omega_{\mathrm{s}}$ are the stator rotating angular speed and the slip speed, respectively. According to (5), the torque slope can be expressed as:

$$
\frac{d T_{e}}{d t}=k_{1} \operatorname{Im}\left\{\frac{d \vec{\psi}_{r}^{*}}{d t} \vec{\psi}_{s}+\vec{\psi}_{r}^{*} \frac{d \vec{\psi}_{s}}{d t}\right\}
$$

Substituting (2) and (7) into (8) yields:

$$
\frac{d T_{e}}{d t}=k_{1} \operatorname{Im}\left\{\vec{v}_{r}^{*} \vec{\psi}_{s}-R_{r} \vec{i}_{r}^{*} \vec{\psi}_{s}+j \omega_{s} \vec{\psi}_{r}^{*} \vec{\psi}_{s}\right\}
$$

Combining (3), (4) and (9) yields:

$$
\frac{d T_{e}}{d t}=k_{1}\left[\operatorname{Im}\left\{\vec{v}_{r}^{*} \vec{\psi}_{s}\right\}-k_{2} \operatorname{Im}\left\{\vec{\psi}_{r}^{*} \vec{\psi}_{s}\right\}+\omega_{s} \operatorname{Re}\left\{\vec{\psi}_{r}^{*} \vec{\psi}_{s}\right\}\right]
$$

On the other hand, the flux slope can be deduced in this way.

$$
\frac{d\left|\vec{\psi}_{r}\right|^{2}}{d t}=\frac{d\left(\vec{\psi}_{r}^{*} \vec{\psi}_{r}\right)}{d t}=2\left|\vec{\psi}_{r}\right| \frac{d\left|\vec{\psi}_{r}\right|}{d t}
$$

Substituting (2) into (11) yields:

$$
\frac{d\left|\vec{\psi}_{r}\right|}{d t}=\frac{1}{\left|\vec{\psi}_{r}\right|}\left[\operatorname{Re}\left\{\vec{v}_{r}^{*} \vec{\psi}_{r}\right\}-R_{r} \operatorname{Re}\left\{\vec{\psi}_{r}^{*} \vec{i}_{r}\right\}\right]
$$

Combining (3), (4) and (12) yields:

$$
\frac{d\left|\vec{\psi}_{r}\right|}{d t}=\frac{1}{\left|\vec{\psi}_{r}\right|}\left[\operatorname{Re}\left\{\vec{v}_{r}^{*} \vec{\psi}_{r}\right\}-k_{3}+k_{4} \operatorname{Re}\left\{\vec{\psi}_{r}^{*} \vec{\psi}_{s}\right\}\right]
$$

In the previous equations, $k_{1}=3 p \lambda L_{m} / 2, \quad k_{2}=\lambda R_{r} L_{s}$, $k_{3}=\lambda R_{r} L_{s}\left|\psi_{r}\right|^{2}, k_{4}=\lambda R_{r} L_{m}$. Both (10) and (13) can be used in steady and transient state because they present the accurate values of the slopes of torque and flu $x$ at any time, any rotor flux position, as illustrated in Fig. 2 (only sub-synchronism is shown). The torque and flux slopes are essential in the proposed PDTC strategy, which will be discussed in the next section. 


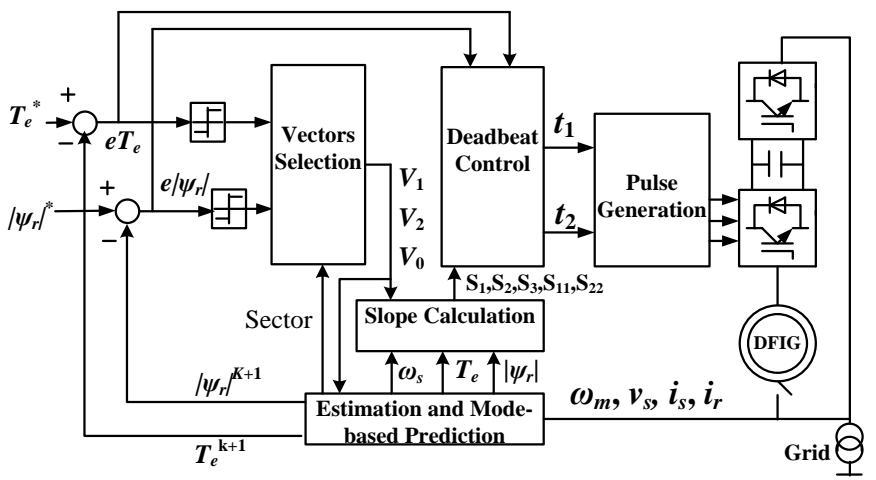

Fig. 3. Control block of proposed PDTC strategy

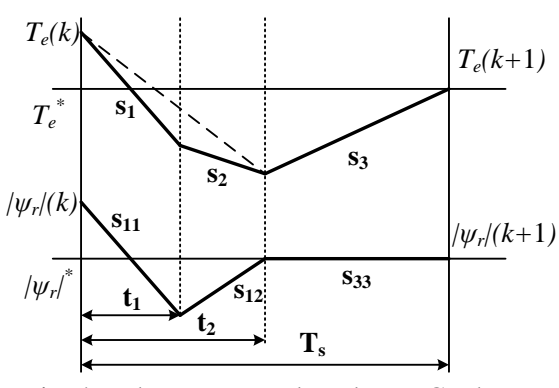

Fig. 4. Three vectors-based PDTC scheme

\section{PROPOSED PDTC STRATEGY OF DFIG}

\section{A. Control diagram of Proposed PDTC Strategy}

The schematic diagram of the proposed PDTC for a DFIG system is shown in Fig. 3. First, the practical value of electromagnetic torque and rotor flux are measured, which will be compared with the referenced value. The errors are delivered to ON-OFF comparators without hysteresis bands, the output of which together with the rotor flux position determine the voltage vector sequences for the next sampling period. The slopes of the torque and flux produced by the voltage vector sequences are then computed respectively. After that the vectors applied duration can be calculated in a deadbeat fashion, which will be delivered to pulse generation block to produce switching signals.

\section{B. Principle of Proposed PDTC Strategy}

Two active vectors and one zero vector are used during every sampling period in this strategy, their durations are calculated at the beginning of the sampling period with the purpose of eliminate the torque and flux errors at the end of the sampling period.

According to (10), (13) and Fig. 2, important information can be drawn. First, at any rotor flu x position, the flux slope is almost equal to zero, on the other hand, the torque slope is very small and it is positive in sub-synchronism and negative in hyper-synchronism (Info. 1). Second, at any sector, no matter sub-synchronism or hyper-synchronism, there are always only two active vectors that produce uniform negative or positive torque slope while these two active vectors
TABLE I

NOVEL VECT ORS SELECTION T ABLE

\begin{tabular}{|c|c|c|}
\hline$e\left|\psi_{r}\right|$ & 1 & -1 \\
\hline 1 & $\mathrm{~V}_{\mathrm{k}-1}$ & $\mathrm{~V}_{\mathrm{k}+1}$ \\
\hline-1 & $\mathrm{~V}_{\mathrm{k}-2}^{\top}$ & $\mathrm{V}_{\mathrm{k}+2}^{\top}$ \\
\hline
\end{tabular}

produce negative and positive flux slope, respectively (Info. 2). Therefore, if two active vectors followed by a zero vector are applied in one sampling period, both torque and flu $\mathrm{x}$ can be regulated effectively. For example, if the rotor flux is within the third sector at sub-synchronism, $T_{e}(k)>T_{e}{ }^{*}$ and $\left|\boldsymbol{\psi}_{r}\right|(k)>\left|\boldsymbol{\psi}_{r}\right|^{*}$, as shown in Fig. 4, $V_{5}$ producing both negative torque and flu $\mathrm{x}$ slope is selected as the first active vector from the classic DTC table with the purpose of correcting the torque and flux error. Next $V_{4}$ producing negative torque slope and positive flux slop is selected as the second active vector. Finally, zero vector producing very small variations is utilized. Actually, using $V_{5}$ and $V_{4}$, both the torque and flux can be controlled, furthermo re combining the zero vector, the torque and flux can be reduced greatly. Now let us look back at the second active vector, we can find something interesting that $V_{4}$ is exactly the vector that should be chosen according to the classic DTC table if $T_{e}(k)>T^{*}$ and $\left|\boldsymbol{\psi}_{r}\right|(k)<\left|\boldsymbol{\psi}_{r}\right|^{*}$ at third sector.

To summarize, the vectors are arranged in this way: The first active vector is selected according to the basic principle of classic DTC table which is determined by the output of ON-OFF comparators without hysteresis bands. If the first active vector is $V_{k-1}$, the second active vector is $V_{k-2}$, vice versa; if the first active vector is $\mathrm{V}_{\mathrm{k}+1}$, the second one is $V_{k+2}$, vice versa. Finally, in order to reduce switching power losses, $V_{0}$ is selected if the second active vector is $V_{2,4,6}$, otherwise, $V_{7}$ is selected. Compared to the method of [8], in this novel strategy, only one simple vectors selection table (TABLE I) is used regardless of motor mode or generator mode, sub- or hyper-s ynchronism, steady state or transient state.

After three vectors are selected, the duty ratio or the vectors duration is calculated in a deadbeat fashion in order to achieve torque and flux ripple reduction at constant switching frequency.

$$
\begin{aligned}
& t_{1}=\frac{\left(\left|\vec{\psi}_{r}\right|^{*}-\left|\vec{\psi}_{r}\right|(k)\right)\left(s_{2}-s_{3}\right)-\left(T^{*}-T_{e}(k)\right) s_{22}+t_{s} s_{22} s_{3}}{s_{11}\left(s_{2}-s_{3}\right)+s_{22}\left(s_{3}-s_{1}\right)} \\
& t_{2}=\frac{\left(\left|\vec{\psi}_{r}\right|^{*}-\left|\vec{\psi}_{r}\right|(k)\right)\left(s_{2}-s_{1}\right)+\left(T^{*}-T_{e}(k)\right)\left(s_{11}-s_{22}\right)+t_{s}\left(s_{22}-s_{11}\right) s_{3}}{s_{11}\left(s_{2}-s_{3}\right)+s_{22}\left(s_{3}-s_{1}\right)}
\end{aligned}
$$

\section{Model-based Predictive One-step Delay Compensation}

In practical digital implementation, the vector $\vec{v}_{r}{ }^{k}$ is decided at $k$ th sampling instant, but it is not applied until the $(k+1) t h$ sampling instant. However, the system variables $\vec{x}^{k}$ 
TABLE I

SYSTEM AND MACHINE PARAMETERS

\begin{tabular}{lccr} 
Rated Power & $15 \mathrm{~kW}$ & $R_{s}$ & $0.168 \Omega$ \\
Rated stator voltage & $380 \mathrm{~V}$ & $R_{r}$ & $0.199 \Omega$ \\
Rated stator current & $55 \mathrm{~A}$ & $L_{s}$ & $0.050 \mathrm{H}$ \\
Rated torque & $95 \mathrm{Nm}$ & $L_{r}$ & $0.050 \mathrm{H}$ \\
Number of pole pairs & 2 & $L_{m}$ & $0.045 \mathrm{H}$ \\
\hline
\end{tabular}

has evolved into $\vec{x}^{k+1}$ at the $(k+1)$ th instant. As a result, the vector applied at the $(k+1) t h$ instant which was decided at $k t h$ sampling instant is not necessary the best one [12]. It should be noted that compensating the one-step delay is very necessary for predictive control, otherwise, the performance improvement compared to basic direct control will be deteriorated, especially when the sampling frequency is low. In this paper, model-based prediction is employed to eliminate the one-step delay. According to (1) and (2), at the kth sampling instant, $\vec{\psi}_{s}{ }^{k+1}$ and $\vec{\psi}_{r}{ }^{k+1}$ can be estimated from $\vec{\psi}_{s}{ }^{k}$, $\vec{i}_{s}^{k}, \vec{\psi}_{r}{ }^{k}$ and $\vec{i}_{r}^{k}$, respectively:

$$
\begin{gathered}
\vec{\psi}_{s}^{k+1}=\vec{\psi}_{s}^{k}+\left(\vec{v}_{s}{ }^{k}-R_{s} \vec{i}_{s}^{k}-j \omega_{r} \vec{\psi}_{s}^{k}\right) T_{s} \\
\vec{\psi}_{r}{ }^{k+1}=\vec{\psi}_{r}{ }^{k}+\left(\vec{v}_{r}{ }^{k}-R_{r} \vec{i}_{r}^{k}\right) T_{s}
\end{gathered}
$$

Substituting (8) and (9) into (5), predictive $T_{e}^{\mathrm{k}+1}$ can be obtained, $T_{e}^{\mathrm{k}+1}$ and $\vec{\psi}_{r}{ }^{k+1}$ are then used to determine $\vec{v}_{r}{ }^{k+1}$, which will be applied at the $(k+1) t h$ sampling instant rather than $\vec{v}_{r}{ }^{k}$.

\section{SYSTEM SIMPLIFICATION AND INVESTIGATION OF PARAMETER VARIATION}

Neglect the rotor copper loss of (2), substituting $\vec{v}_{r}=d \vec{\psi}_{r} / d t$ into (12), flux slope can be simplified as

$$
\frac{d\left|\vec{\psi}_{r}\right|}{d t}=\frac{1}{\left|\vec{\psi}_{r}\right|} \operatorname{Re}\left\{\vec{v}_{r}^{*} \vec{\psi}_{r}\right\}
$$

In the similar way, it is not difficult to deduce that torque slope can also be simplified as

$$
\frac{d T_{e}}{d t}=k_{1}\left[\operatorname{Im}\left\{\vec{v}_{r}^{*} \vec{\psi}_{s}+\omega_{s} \operatorname{Re}\left\{\vec{\psi}_{r}^{*} \vec{\psi}_{s}\right\}\right]\right.
$$

On the other hand, given that leakage inductance is much small compared to the mutual inductance, i.e. $L_{m}>L_{l s}$ and $L_{m}>L_{l r}, k_{1}$ can be simplified without mutual inductance $L_{m}$ as follow:

$$
\begin{aligned}
k_{1} & =\frac{3}{2} p \lambda L_{m} \\
& =\frac{3}{2} p \frac{L_{m}}{\left(L_{l s}+L_{m}\right)\left(L_{l r}+L_{m}\right)-L_{m}^{2}} \\
& =\frac{3}{2} p \frac{L_{m}}{L_{m}\left(L_{l s}+L_{l r}\right)-L_{l s} L_{l r}}
\end{aligned}
$$
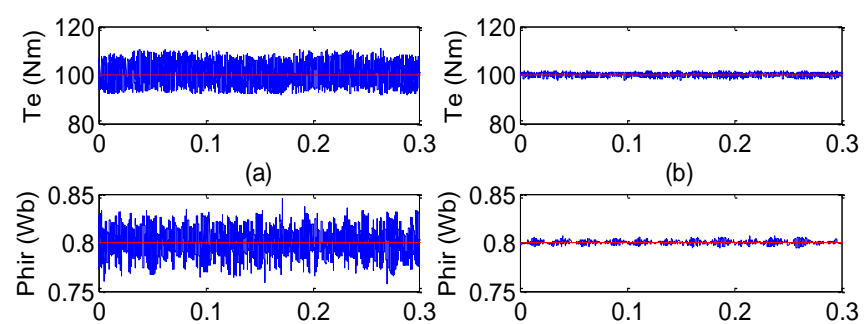

(c)
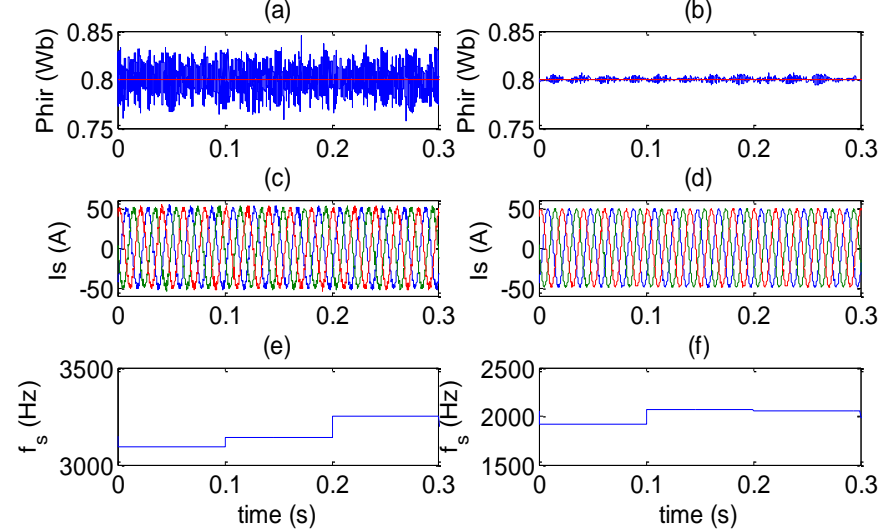

(g)

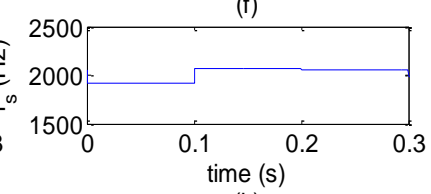

(h)

Fig. 5. Steady-state performance of CDTC and proposed PDTC. (a) electromagnetic torque of CDTC, (b) electromagnetic torque of PDTC, (c) rotor flux of CDTC, (d) rotor flux of PDTC, (e) stator current of CDTC, (f) stat 4 Peurrent of PDTC, (g) switching frequency of CDTC, (h) switching frequency of PDTC.

$$
\downarrow \quad \uparrow \approx \frac{3}{2} p \frac{1}{L_{l s}+L_{l r}}
$$

Thereftre, (15) can be simplified further:

$$
\frac{d T_{e}}{d t}=\frac{3}{2} p \frac{1}{L_{l s}+L_{l r}}\left[\operatorname{Im}\left\{\vec{v}_{r}^{*} \vec{\psi}_{s}+\omega_{s} \operatorname{Re}\left\{\vec{\psi}_{r}^{*} \vec{\psi}_{s}\right\}\right]\right.
$$

After deduction, the slope equations of torque and flux are much simpler. Simulation result shows that this simplicity is guaranteed without performance degradation.

\section{$\Delta P$}

\section{SiMULATION RESUlTS}

$\Delta$ The main system and generator parameters are listed in Table II. The simu lation test platform is setup according to Fig. 3. For the sake of simplicity, the dc-link voltage of the back-toback converters is $\downarrow$ et to $500 \mathrm{~V}$ constantly. It is noted that onestep delas has peen compensated based on model-based prediction in all tests.

\section{A. Comparison of CDTC and Proposed PDTC}

The sampling frequencies of CDTC and PDTC are $10 \mathrm{kHz}$ and $4 \mathrm{kHz}$. The machine is operating at steady state with constant $1300 \mathrm{rev} / \mathrm{min}$ rotating speed as mechanical input, the referenced torque is $100 \mathrm{Nm}$ while the referenced rotor flux is set $0.8 \mathrm{~Wb}$. The switching frequency is computed by counting the switch operation state of a phase leg within a fixed period. As shown in Fig. 5(a)-(d), the torque and flux ripples of proposed PDTC are much small than that of CDTC. Stator curpent performance can be found in Fig. 5 (e) and (f). From Fig. $5(\mathrm{~g})$ and (f), we can find that the switching frequency of CDTC varies between $3 \mathrm{kHz}$ and $3.5 \mathrm{kHz}$ while almost constant switching frequency is obtained at $2 \mathrm{kHz}$ for PDTC. 

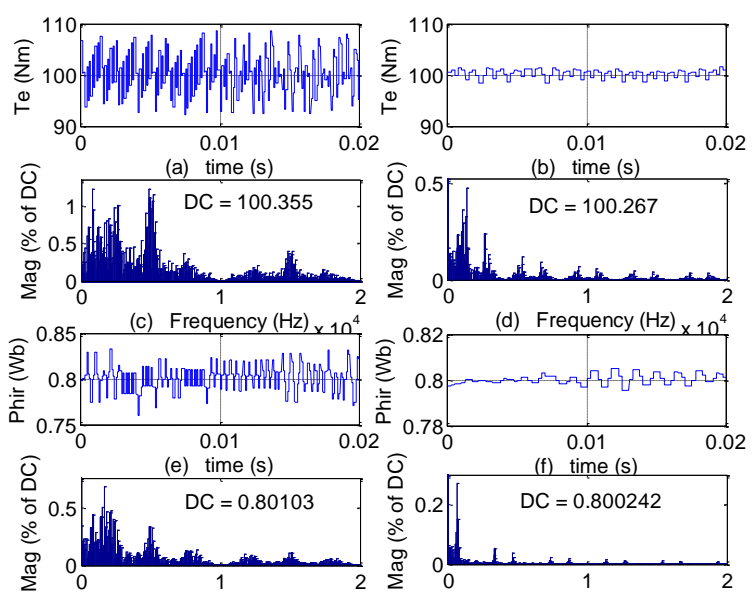

(g) Frequency $(\mathrm{Hz}) \times 10^{4}$
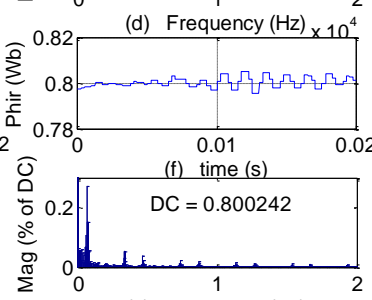

(h) Frequency $(\mathrm{Hz}) \times 10^{4}$

Fig. 6. Torque and flux zooms and spectrums. (a) torque zoom (CDTC), (b) torque zoom (PDTC), (c) torque spectrums (CDTC), (d) torque spectrums (PDTC) , (e) flux zoom (CDTC), (f) flux zoom (PDTC), (g) flux spectrums (CDTC), (h) flux spectrums (PDTC).

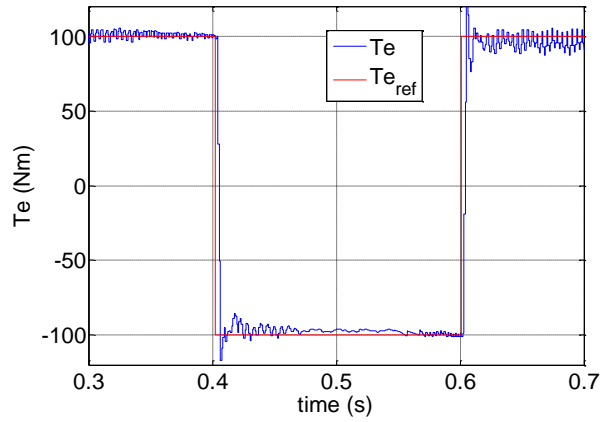

(a)
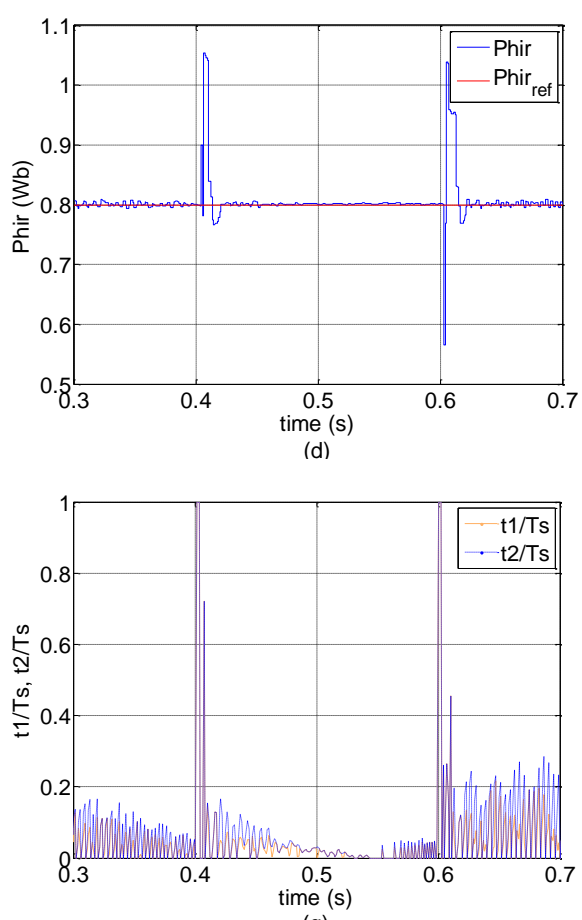

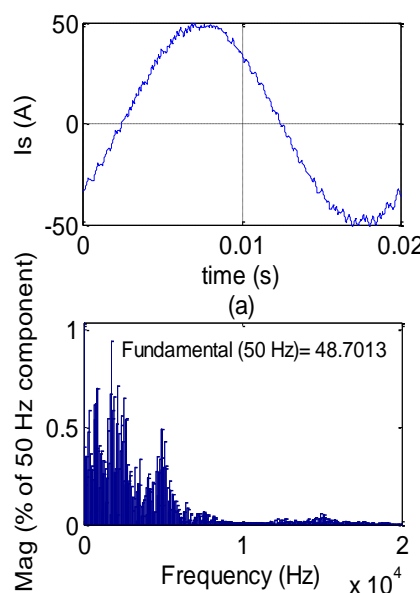

Fig. 7. Stator current zooms and spectrums. (a) zoom (CDTC), (b) zoom (PDTC), (c) THD=3.64\% (CDTC), (d) THD=0.84\% (PDTC).

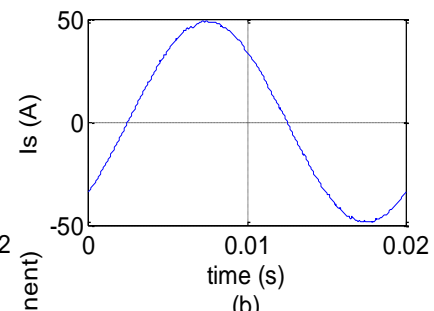

(b)

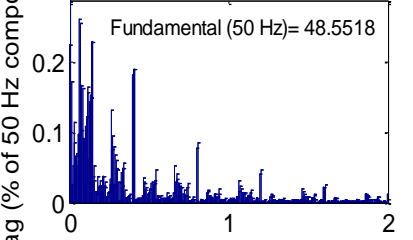

DTC), (b) zoom
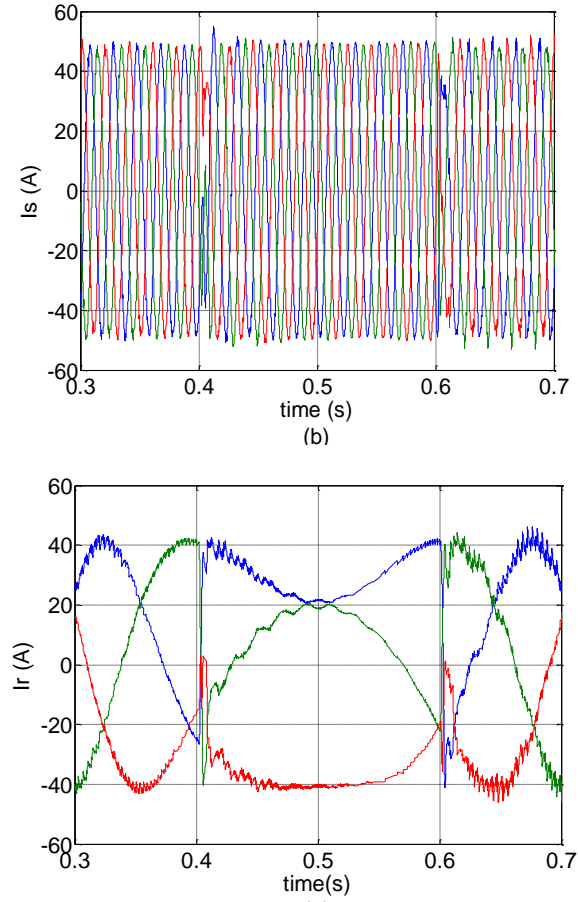

(e)
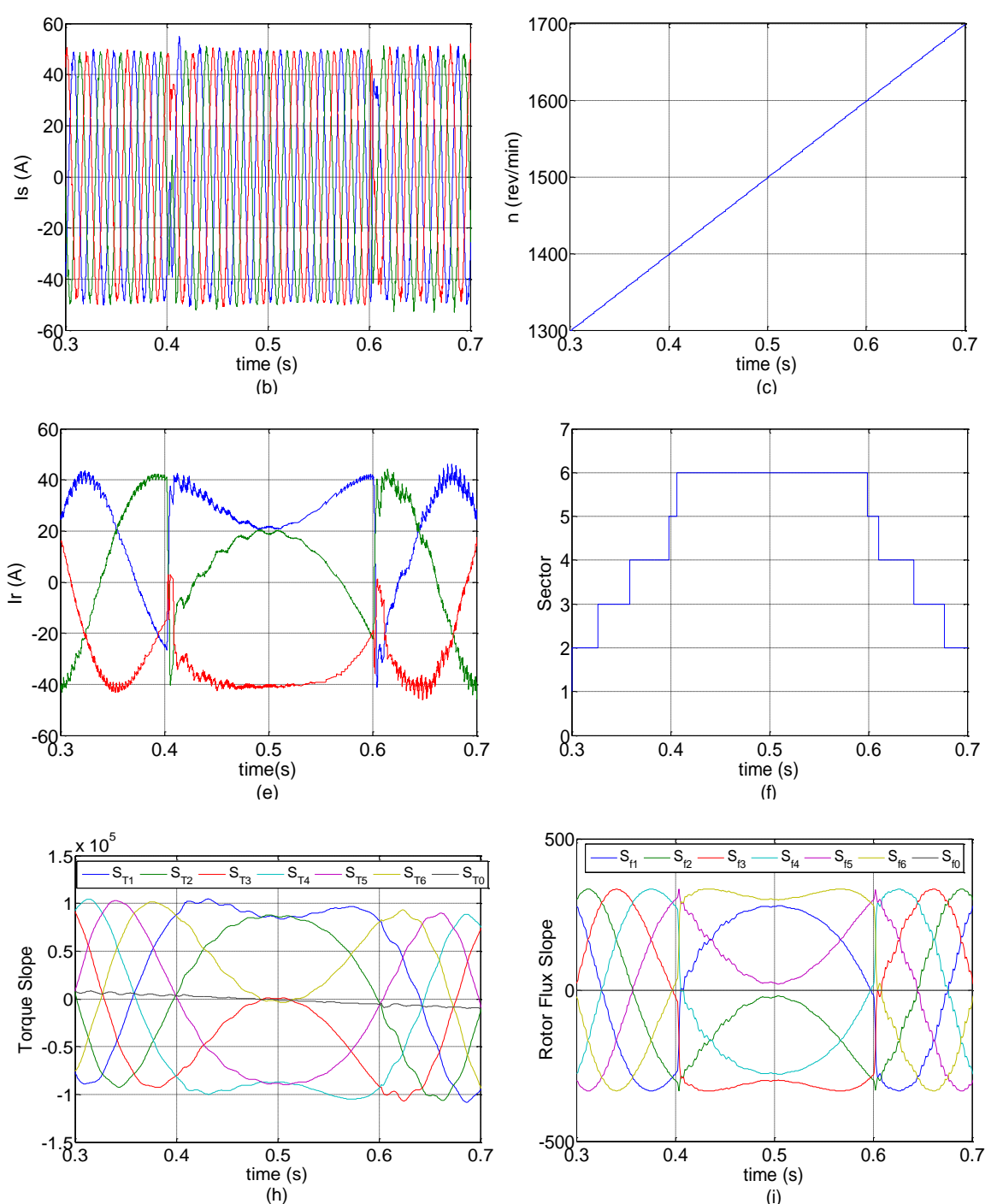

Fig. 8. Dynamic performance at $500 \mathrm{~Hz}$ switching frequency. (a) electromagnetic torque, (b) stat or currents, (c) rotor speed, (d) rotor flux, (e) rotor currents, (f) rotor flux sector, $(\mathrm{g})$ vectors applying duty cycles, (h) electromagnetic torque slopes, (i) rotor flux slopes. 
Torque and flux ripples reduction can be validated more clearly by analyzing torque and current zooms and spectrums. As depicted in Fig. 6, for CDTC and PDTC, the torque fluctuating ranges are $\pm 8 \mathrm{Nm}$ and only $\pm 1.5 \mathrm{Nm}$, respectively. The rotor flux fluctuating ranges are $\pm 0.4 \mathrm{~Wb}$ for CDTC and only $\pm 0.05 \mathrm{~Wb}$ for PDTC. Furthermore, the dominant harmonic components exist at $4 \mathrm{kHz}$ and its multiples for PDTC because of almost constant switching frequency behavior with this control strategy. On the other hand, the total harmonic distortion (THD) of the stator currents with PDTC is much smaller than that of the stator currents with CDTC though the spectrum of Fig. 7(c) presents a more dense property than that of Fig. 7(d).

\section{B. Dynamic Performance at Low Switching frequency}

At transient response test, the sampling frequency is set to 1 $\mathrm{kHz}$ and the system operates at $500 \mathrm{~Hz}$ switching frequency when the speed of the machine increases from $1300 \mathrm{rev} / \mathrm{min}$ at $0.3 \mathrm{~s}$ to $1700 \mathrm{rev} / \mathrm{min}$ at $0.7 \mathrm{~s}$ gradually while the referenced torque steps down to $-100 \mathrm{Nm}$ at $0.4 \mathrm{~s}$ and rises abruptly back to $100 \mathrm{Nm}$ at $0.6 \mathrm{~s}$. The electromagnetic torque can track the command fast with excellent dynamic performance though there are obvious flux overshoots when at $0.4 \mathrm{~s}$ and $0.6 \mathrm{~s}$, as shown in Fig. 8(a) and (d). The stator and rotor currents are shown in Fig. 8(b) and (e), respectively. The rotor current becomes direct current near synchronis $m$ while a phase change can be observed both in stator and rotor current at $0.4 \mathrm{~s}$ and 0.6 $\mathrm{s}$ when the sign of the torque reverses, i.e. from motor-mode to generator-mode or from generator-mode to motor-mode.

On the other hand, it is very necessary to emphasize that in order to track the rapidly changed referenced torque in a short instant, only two vectors or even one vector is applied during a sampling period, as depicted in Fig. 8(g). For example, at $0.4 \mathrm{~s}$ and $0.6 \mathrm{~s}$, only the first active vector (the second active vector and the zero vector are not used) is selected because it is the one producing the largest torque variation to achieve excellent dynamic performance. The real-time slope trajectories of torque and flux calculated from (14) and (16) can be observed at Fig. 8(h) and (i).

\section{CONCLUSIONS}

This paper presents an improved predictive direct torque control strategy for DFIG. The torque and flux ripples can be reduced significantly and low constant switching frequency is achieved with the proposed PDTC while the simplicity and robustness of the CDTC is inherited at the most. The proposed strategy is every suitable for wind power generation application. For example, it can be employed to direct virtual torque control of DFIG for grid synchronization by replacing the electromagnetic torque reference with virtual torque reference during the grid connection process [13,14]. After connected to the grid, in electrical power generation process, it can also be used for flexible active power and reactive power regulation by changing the torque and flux control loops to active and reactive power control loops, and at the same time calculating the power slopes in a similar way.

\section{REFERENCES}

[1] I. Takahashi and T. Noguchi, "A new quick-response and high efficiency control strategy of an induction machine," IEEE Trans. Ind. Appl., vol. IA-22, pp 820-827, 1986.

[2] M. Depenbrock, "Direct self control of inverter-fed induction machines," IEEE Trans. Power Electron ., vol. 3, pp 420-429, 1988.

[3] F. Blaschke, "The principle of field-orientation as applied to the transvector closed-loop control system for rotating-field machines," in Siemens Rev.vol.34,pp.217-220,1972.

[4] G. S. Buja and M. P. Kazmierkowski, "Direct torque control of PWM inverter-fed AC motors - A Survey," IEEE Trans. Industry Electron, vol. 1, no. 4, pp. 744-757, 2004.

[5] C. Lascu and A. M. Trzynadlowski, "Combining the principles of sliding mode, direct torque control, and space-vector modulation in a highperformance sensorless AC drive," IEEE Trans. Ind. Appl., vol. 40, no. 1, pp. 170-177, 2004.

[6] N. R. N. Idris and A. H. M. Yatim, "Direct torque control of induction machines with constant switching frequency and reduced torque ripple," IEEE Trans. Ind. Electron., vol. 51, pp. 758-767, 2004.

[7] L. Yongheng, F. Xiaoyun, Z. Xiaohao, and W. Yanzhi, "Research and simulation on constant switching frequency of direct torque control(DTC)," in Conf. International Conference on Electrical Machines and Systems (ICEMS 2008), pp. 1329-1333, 2008.

[8] G. Abad, M. A. Rodriguez, and J. Poza, "Two-Level VSC Based Predictive Direct Torque Control of the Doubly Fed Induction Machine With Reduced Torque and Flux Ripples at Low Constant Switching Frequency," IEEE Trans. Power Electron., vol. 23, no. 3, pp. 1050$1061,2008$.

[9] D. Zhi, L. Xu, and B. W. Willianms, "Model-based predictive direct power control of doubly fed induction generators," IEEE Trans. Power Electron., vol. 25, no. 2, pp. 341-351, 2010.

[10] Y. C. Zhang, J. G. Zhu and W. Xu, "Predictive torque control of permanent magnet synchronous motor drive with reduced switching frequency," in Conf. International Conference on Electrical Machines and Systems (ICEMS 2010) , pp. 798-803, 2010.

[11] J. Beerten, J. Verveckken and J. Driesen, "Predictive direct torque control for flux and torque ripple reduction," IEEE Trans. Ind. Electron., vol. 57, no. 1, pp. 404-412, 2010.

[12] Y. Zhang, J. Zhu, and W. Xu, "Analysis of one step delay in direct torque control of permanent magnet synchronous motor and its remedies," in Proc. Int Electrical Machines and Systems (ICEMS) Conf, 2010, pp. 792-797.

[13] Y. Zhang, J. Zhu, and J. Hu, "Model predictive direct torque control for grid synchronization of doubly fed induction generator," in Proc. IEEE Int. Electric Machines and Drives Conf. IEMDC'11, 2011, pp. 1-6.

[14] J. Arbi, M. J.-B. Ghorbal, I. Slama-Belkhodja, and L. Charaabi, "Direct virtual torque control for doubly fed induction generator grid connection," IEEE Trans. Ind. Electron., vol. 56, no. 10, pp. 4163-4173, 2009. 